\title{
Association between Diastolic Dysfunction by Color Tissue Doppler Imaging and Vascular Calcification on Plain Radiographs in Dialysis Patients
}

\author{
Won Suk An a, c Su Mi Lee ${ }^{\mathrm{a}}$ Tae Ho Park ${ }^{\mathrm{a}}$ Seong Eun Kim ${ }^{\mathrm{a}}$ Ki Hyun Kimª \\ Young Jin Park ${ }^{b}$ Young Ki Son ${ }^{a}$ \\ Departments of ${ }^{a}$ Internal Medicine and ${ }^{b}$ Family Medicine, and ${ }^{c}$ Institute of Medical Science, \\ Dong-A University College of Medicine, Busan, Republic of Korea
}

\section{Key Words}

Dialysis · Diastolic dysfunction • Echocardiography •

Radiography $\cdot$ Vascular calcification

\begin{abstract}
Background/Aim: Diastolic dysfunction is frequently associated with left ventricular hypertrophy, which is indicative of future cardiovascular events. Vascular calcification (VC) is known to be associated with coronary artery disease in dialysis patients. The present study was to determine the interrelationship between $\mathrm{LV}$ diastolic dysfunction by tissue Doppler imaging and VC on plain radiographs in dialysis patients. Methods: Fifty-six dialysis patients were recruited and VC scores were evaluated by plain radiographic film. The ratio of early diastolic transmitral inflow velocity $(E)$ to early diastolic mitral annular velocity ( $\left.E^{\prime}\right)$ was measured by tissue Doppler imaging. We defined diastolic dysfunction as an E/E' ratio $>15$ on tissue Doppler imaging. Results: Patients with diastolic dysfunction showed a higher percentage of coronary artery disease history, abdominal aortic calcification (AAC) scores $\geq 5$, high LV mass index, and high left atrium volume compared to patients without diastolic dysfunction. The $E / E^{\prime}$ ratio was significantly higher in patients with significant VC, VC scores of the pelvis and hands $\geq 3$, and AAC scores $\geq 5$ on plain radiographs. AAC scores $\geq 5$ were
\end{abstract}

considered an independent predictor of diastolic dysfunction. Conclusion: VC on plain radiographs is associated with the $E / E^{\prime}$ ratio and $A A C$ scores $\geq 5$ are important clues for $L V$ diastolic dysfunction in dialysis patients.

Copyright $\odot 2012$ S. Karger AG, Base

\section{Introduction}

The prevalence of left ventricular (LV) changes, especially LV hypertrophy, is high among patients with chronic kidney disease and end-stage renal disease [1]. The risk of heart failure is threefold higher in uremic patients with LV hypertrophy, LV dilatation, and systolic dysfunction on echocardiograph regardless of age, diabetes, and coronary artery disease (CAD) [2]. Diastolic dysfunction assessed by echocardiography is a common sequela of arterial hypertension, which usually occurs early even before the manifestation of systolic dysfunction. Arterial stiffness and diastolic LV dysfunction are interrelated and frequently found in patients with diabetes mellitus and essential hypertension $[3,4]$. Increased arterial stiffness or high pulse pressure are also related to vascular calcification (VC) in dialysis patients [5]. Therefore, LV diastolic dysfunction is thought to be possibly associated with VC.

\section{KARGER}

Fax +4161306 1234

E-Mail karger@karger.ch

www.karger.com
(C) 2012 S. Karger AG, Basel

$1420-4096 / 12 / 0356-0619 \$ 38.00 / 0$

Accessible online at:

www.karger.com/kbr 
Cardiovascular disease is a major comorbid disease and a frequent cause of hospitalization in dialysis patients [6]. VC is associated with cardiovascular disease and has been shown to be an independent predictor of cardiovascular mortality in dialysis patients $[7,8]$. VC scores of the pelvis and hands from plain radiographic film are independently associated with CAD in hemodialysis (HD) patients at the end of follow-up [9]. Kidney Disease Improving Global Outcomes suggested that a lateral lumbar spine radiograph can be used to detect $\mathrm{VC}$ and is a good predictor of coronary artery calcification [10]. A recent report showed that the prevalence of $\mathrm{CAD}$ is related to the presence of medial artery calcification in the feet on plain radiography [11]. However, there are no reports on the association between $\mathrm{VC}$ on plain radiographs and diastolic dysfunction in dialysis patients.

In this study, we hypothesized that there is a possible interrelationship between LV diastolic dysfunction by tissue Doppler imaging and VC on plain radiographs in dialysis patients. In addition, we evaluated which VC on plain radiographs is more useful for the assessment of diastolic dysfunction in dialysis patients.

\section{Methods}

\section{Patients}

Among $47 \mathrm{HD}$ and 33 peritoneal dialysis (PD) patients who wanted to participate in this study, 56 dialysis patients $(34 \mathrm{HD}$ and 22 PD patients) were recruited from the Dong-A University Dialysis Center. All patients between the ages of 20 and 80 years were considered eligible for the study if they had received dialysis treatment for $\geq 12$ months. Patients with a history of hospital admission within 3 months were excluded. The enrolled HD patients received regular HD 3 times weekly. Bicarbonate-based dialysate and polysulfone dialyzers (Fresenius, Bad Homburg, Germany) were used. The enrolled $\mathrm{PD}$ patients received 4 exchanges per day using a standard regimen (8 1/day). Systolic blood pressure and diastolic blood pressure were measured in the sitting position before $\mathrm{HD}$ and casual blood pressure was taken as the average of 3 consecutive measurements taken just before echocardiography in PD patients. Informed consent was obtained from all enrolled patients. This study was approved by the Dong-A University Hospital Institutional Review Board.

\section{Laboratory Measurements}

Laboratory tests, including hemoglobin, calcium, phosphate, parathyroid hormone, alkaline phosphatase, C-reactive protein, total cholesterol, triglycerides, low-density lipoprotein-cholesterol, high-density lipoprotein cholesterol, blood urea nitrogen, and creatinine were obtained using fasting blood samplings. Additionally, $\mathrm{HbA}_{1 \mathrm{c}}$ was determined in diabetic patients. Blood samples and BMI were both taken before HD and before echocardiography in $\mathrm{PD}$ patients.

\section{Vascular Calcification}

We checked the plain radiographs of the feet, hands, pelvis, and lateral lumbar spine, and estimated the VC scores using previously reported methods. Abdominal aortic calcification (AAC) was graded using a previously reported system in which the location and severity of calcification deposits at each lumbar vertebral segment (L1-L4) were evaluated $[12,13]$. These scores were summarized using two methods: (1) the composite score for anterior-posterior severity in which the scores of individual aortic segments both for the anterior and posterior walls were summed (maximum score of 24), and (2) the affected segment score was calculated as the total number of aortic segments showing any level of calcification indicated (maximum score of 4). It has been reported that an AAC $\geq 5$ increases the risk of cardiovascular disease $[14,15]$. VC scores of the pelvis and hands of the participants were evaluated in plain radiographic films. The radiographic films of the pelvis and hands were divided into four sections by two imaginary lines: a horizontal line over the upper limit of both femoral heads and a median vertical line over the vertebral column. The films of the hands were divided for each hand by a horizontal line over the upper limit of the metacarpal bones. The presence of linear calcifications in each section of the pelvis and the hand was counted as 1 and its absence as 0 . The final score was the sum of all sections, ranging from 0 to 8 . In a previous study, receiver operating characteristic curve analysis identified a VC score $\geq 3$ as the best cutoff value associated with cardiovascular motility and cardiovascular events [9]. On radiographs of the feet, a score of 0 was assigned when medial artery calcification of the feet was absent, and a score of 1 was assigned when VC was present. Each VC serves as a useful predictor for cardiovascular disease. However, a study showed that VC evaluation on plain radiographs by only single method overlooked nearly $30 \%$ of other significant VC sites in PD and HD patients [16]. Therefore, we checked several plain radiographs and evaluated several VC sites on plain radiographs. We defined significant $\mathrm{VC}$ as any one finding among the following findings on plain radiographs: $\mathrm{AAC}$ score $\geq 5, \mathrm{VC}$ score of the hands and pelvis $\geq 3$, or medial artery calcification of the feet. This was performed by AXIOM Aristors MX/VX (SIEMENS, Erlangen, Germany) radiographic equipment with a digital imaging system [exposure conditions, $45-50 \mathrm{kVp}$ (4 mAs)]. Two nephrologists independently decided VC scores on plain radiographs without any patient information. Consensus was reached on the interpretation of all radiographs.

\section{Echocardiography}

All enrolled patients were scanned with two-dimensional gray-scale imaging using a commercially available machine (Philips Sonos 5500, Andover, Mass., USA) to acquire the standard parasternal and apical images; these were used for the measurement of the cardiac dimensions and ejection fraction. HD patients were scanned by echocardiography after the first dialysis session of the week. The LV ejection fraction was obtained using a modified biplane Simpson's method from apical and four-chamber views. Measurements for M-mode-guided calculations of LV mass were taken at or just below the tip of the mitral valve with a paper speed of $50 \mathrm{~mm} / \mathrm{s}$. The LV mass was calculated using the modified American Society of Echocardiography cube formula and indexed by body surface area [17]. Using a pulsed-wave Doppler, mitral inflow profiles such as the peak 
early (E-wave), late (A-wave) diastolic velocities, and E-deceleration time were measured according to previously recommended methods [18].

Tissue Doppler velocities of the mitral annulus were obtained from the apical 4-chamber view. A sample volume was placed consecutively at the lateral and medial mitral annulus. The ratio of early diastolic peak transmitral inflow velocity to early diastolic mitral annular velocity (E/E' ratio) was checked for estimation of LV filling pressure. An increase of this ratio is known to be correlated with the presence of diastolic dysfunction [19]. Based on other studies, we defined diastolic dysfunction as E/E' ratio $>15$ [20-22].

We counted the number of heart valve calcifications (range: $0-4)$ on echocardiography. Valve calcification was defined as bright echoes $>1 \mathrm{~mm}$ on one or more valve cusps. All findings on echocardiography were interpreted by an experienced cardiologist who was blinded to the clinical and laboratory data.

\section{Statistical Analysis}

Data are presented as means \pm SD except for dietary consumption data which are expressed as means \pm SE. The nonparametric Mann-Whitney U test was used to compare numerical data between patients with and without significant calcification. Fisher's exact test was used to compare dichotomous data between patients with and without significant calcification. A Mann-Whitney $U$ test was used to compare numerical data and Fisher's exact test was used to compare dichotomous data between patients with an $\mathrm{E} / \mathrm{E}^{\prime}$ ratio $\leq 15$ and patients with an $\mathrm{E} / \mathrm{E}^{\prime}$ ratio $>15$. Correlation analyses were performed using Spearman's rank test. Multiple linear regression analysis using the backward elimination method was applied to determine the factors independently associated with the $\mathrm{E} / \mathrm{E}^{\prime}$ ratio on tissue Doppler imaging since $\mathrm{E} / \mathrm{E}^{\prime}$ ratio was a continuous variable. We included age, LV mass index, left atrium (LA) volume, CAD history, significant VC, AAC scores $\geq 5$, and VC scores of the hand and pelvis $\geq 3$ as independent factors for linear regression analysis. Logistic regression analysis was also used for analysis to determine the factors independently associated with diastolic dysfunction since diastolic dysfunction was a dichotomous variable. We included age, CAD history, significant VC, AAC scores $\geq 5$, $\mathrm{VC}$ scores of hand and pelvis $\geq 3$, and number of antihypertension medications as independent factors for logistic regression analysis. We selected clinical variables for logistic regression analysis because these variables were related with VC or diastolic dysfunction. $\mathrm{p}<0.05$ was considered significant. All statistical calculations were performed with SPSS software, version 16.0 (SPSS Inc., Chicago, Ill., USA).

\section{Results}

Characteristics of Patients According to Significant VC The study population consisted of 56 dialysis patients with a mean duration of renal replacement therapy of $38.9 \pm 28.7$ months. The group consisted of 22 men and 34 women, with a mean age of $55.2 \pm 10.2$ years and a mean $\mathrm{E} / \mathrm{E}^{\prime}$ ratio of $10.6 \pm 4.2$. The clinical and biochem- ical characteristics of patients according to the presence of significant VC are summarized in table 1.

The prevalence of diabetes and CAD history were significantly higher in patients with significant VC than in those without significant $\mathrm{VC}$. The E/E' ratio and LV mass index were higher in patients with significant $\mathrm{VC}$ than in those without significant VC $(11.7 \pm 4.5$ vs. $8.9 \pm 3.0$, $\mathrm{p}=0.031 ; 119.7 \pm 27.2$ vs. $\left.93.8 \pm 45.8 \mathrm{~g} / \mathrm{m}^{2}, \mathrm{p}=0.031\right)$. The serum high-density lipoprotein cholesterol level was significantly lower and the C-reactive protein level was significantly higher in patients with significant $\mathrm{VC}$ than in those without significant VC. The prevalence of diastolic dysfunction was $23.5 \%$ (8 patients) in patients with significant VC and 4.5\% (1 patient) in patients without significant VC.

\section{Characteristics of Patients According to Diastolic Dysfunction}

Of the 56 patients, 47 patients (83.9\%) had an E/E' ratio $\leq 15$ and 9 patients (16.1\%) had an $E / E^{\prime}$ ratio $>15$. The clinical and biochemical characteristics of patients according to the presence of diastolic dysfunction are summarized in table 2. Patients with diastolic dysfunction showed higher percentages of CAD history, AAC scores $\geq 5$, and high LV mass index and LA volume compared to patients without diastolic dysfunction. Patients with diastolic dysfunction took a lot more antihypertensive medications and showed lower ejection fraction compared to patients without diastolic dysfunction.

\section{E/E' Ratio According to VC Sites on Plain \\ Radiographs}

The $\mathrm{E} / \mathrm{E}^{\prime}$ ratio was significantly higher in patients with significant VC compared to those without significant VC $(\mathrm{p}=0.015)$. The $\mathrm{E} / \mathrm{E}^{\prime}$ ratio was significantly higher in patients with VC scores of the pelvis and hands $\geq 3$, and with AAC scores $\geq 5$ compared to patients with VC scores of the pelvis and hands $<3$, and with AAC scores $<5$. There was no significant difference in $\mathrm{E} / \mathrm{E}^{\prime}$ ratios according to the presence of arterial media calcification on the feet (fig. 1). The E/E' ratio was positively correlated with significant $\mathrm{VC}(\mathrm{r}=0.325, \mathrm{p}=0.015)$, AAC scores $\geq 5(\mathrm{r}=$ $0.396, \mathrm{p}=0.003)$, and VC scores of the pelvis and hands $\geq 3$ ( $\mathrm{r}=0.342, \mathrm{p}=0.010)$, but was not related with arterial media calcification on the feet (table 3 ).

\section{Factors Associated with E/E' Ratio and Diastolic Dysfunction}

The $\mathrm{E} / \mathrm{E}^{\prime}$ ratio was positively correlated with $\mathrm{LV}$ mass index $(\mathrm{r}=0.351, \mathrm{p}=0.009)$, LA volume $(\mathrm{r}=0.608, \mathrm{p}<$ 
Table 1. Characteristics of study population according to significant vascular calcification

\begin{tabular}{|c|c|c|c|c|}
\hline \multirow[t]{2}{*}{ Characteristics } & \multirow[t]{2}{*}{ Total } & \multicolumn{2}{|c|}{ Significant vascular calcification } & \multirow[t]{2}{*}{$\mathrm{p}$} \\
\hline & & positive $(n=34)$ & negative $(\mathrm{n}=22)$ & \\
\hline Age, years & $55.5 \pm 10.2$ & $57.1 \pm 9.7$ & $53.2 \pm 10.8$ & 0.167 \\
\hline Male, n (\%) & $22(39.3)$ & $13(38.2)$ & $9(40.9)$ & 1.000 \\
\hline Diabetes, $\mathrm{n}(\%)$ & $28(50)$ & $22(64.7)$ & $6(27.3)$ & 0.006 \\
\hline CAD history, $\mathrm{n}(\%)$ & $13(23.2)$ & $13(38.2)$ & $0(0)$ & 0.001 \\
\hline $\mathrm{HD} / \mathrm{PD}, \mathrm{n}$ & $34 / 22$ & $22 / 12$ & $12 / 10$ & 0.577 \\
\hline Dialysis duration, months & $38.9 \pm 28.7$ & $41.2 \pm 31.1$ & $35.2 \pm 24.7$ & 0.449 \\
\hline BMI & $23.4 \pm 3.3$ & $23.6 \pm 3.3$ & $23.1 \pm 3.3$ & 0.603 \\
\hline Systolic BP, mm Hg & $146.0 \pm 26.4$ & $148.0 \pm 27.3$ & $142.7 \pm 25.2$ & 0.397 \\
\hline Diastolic BP, mm Hg & $79.6 \pm 14.0$ & $78.4 \pm 15.3$ & $81.6 \pm 11.6$ & 0.526 \\
\hline $\mathrm{LV}$ mass index, $\mathrm{g} / \mathrm{m}^{2}$ & $114.0 \pm 27.5$ & $119.7 \pm 27.2$ & $93.8 \pm 45.8$ & 0.031 \\
\hline Ejection fraction, $\%$ & $57.6 \pm 9.5$ & $56.2 \pm 11.2$ & $59.8 \pm 5.7$ & 0.259 \\
\hline Left atrium volume, $\mathrm{ml}$ & $64.4 \pm 21.5$ & $67.9 \pm 20.5$ & $60.1 \pm 22.4$ & 0.210 \\
\hline Deceleration time, $\mathrm{ms}$ & $247.6 \pm 67.6$ & $241.0 \pm 60.4$ & $254.9 \pm 75.65$ & 0.521 \\
\hline $\mathrm{E} / \mathrm{E}^{\prime}$ ratio & $10.6 \pm 4.2$ & $11.7 \pm 4.5$ & $8.9 \pm 3.0$ & 0.031 \\
\hline Hemoglobin, g/dl & $10.4 \pm 1.0$ & $10.5 \pm 1.0$ & $10.23 \pm 1.1$ & 0.735 \\
\hline $\mathrm{PTH}, \mathrm{pg} / \mathrm{ml}$ & $330.3 \pm 284.7$ & $287.7 \pm 249.6$ & $408.3 \pm 333.4$ & 0.117 \\
\hline Calcium, mg/dl & $8.7 \pm 0.7$ & $8.8 \pm 0.6$ & $8.5 \pm 0.8$ & 0.142 \\
\hline Phosphorous, mg/dl & $4.8 \pm 1.4$ & $4.7 \pm 1.4$ & $4.9 \pm 1.4$ & 0.692 \\
\hline Creatinine, mg/dl & $9.9 \pm 2.9$ & $9.7 \pm 3.1$ & $10.2 \pm 2.6$ & 0.486 \\
\hline ALP, IU/l & $343.9 \pm 232.0$ & $286.9 \pm 135.9$ & $426.5 \pm 310.8$ & 0.115 \\
\hline Cholesterol, mg/dl & $163.2 \pm 43.0$ & $158.1 \pm 34.0$ & $171.1 \pm 54.1$ & 0.276 \\
\hline $\mathrm{HDL}, \mathrm{mg} / \mathrm{dl}$ & $40.7 \pm 10.8$ & $38.3 \pm 10.2$ & $44.1 \pm 10.9$ & 0.034 \\
\hline $\mathrm{LDL}, \mathrm{mg} / \mathrm{dl}$ & $88.4 \pm 35.9$ & $80.8 \pm 25.7$ & $99.4 \pm 45.5$ & 0.256 \\
\hline Triglyceride, mg/dl & $154.5 \pm 100.0$ & $166.2 \pm 115.4$ & $137.1 \pm 70.1$ & 0.410 \\
\hline Albumin, g/dl & $3.9 \pm 0.3$ & $3.9 \pm 0.3$ & $3.9 \pm 0.4$ & 0.467 \\
\hline $\mathrm{CRP}, \mathrm{mg} / \mathrm{dl}$ & $0.4 \pm 0.9$ & $0.6 \pm 1.1$ & $0.2 \pm 0.4$ & 0.001 \\
\hline
\end{tabular}

$\mathrm{BP}=$ Blood pressure; $\mathrm{PTH}=$ parathyroid hormone; $\mathrm{BUN}=$ blood urea nitrogen; $\mathrm{ALP}=$ alkaline phosphatase; $\mathrm{HDL}=$ high-density lipoprotein cholesterol; LDL = low-density lipoprotein cholesterol; CRP = C-reactive protein.

$0.001)$, and CAD history $(\mathrm{r}=0.291, \mathrm{p}=0.029)$. Age, LA volume, and AAC scores $\geq 5$ were independent predictors of a higher $\mathrm{E} / \mathrm{E}^{\prime}$ ratio in multiple linear regression analysis (table 4). AAC scores $\geq 5[\operatorname{Exp}(\mathrm{B})=8.89,95 \%$ CI: $1.36-48.51, \mathrm{p}=0.012]$, CAD history $[\operatorname{Exp}(B)=6.09$, 95\% CI: $1.33-27.83, \mathrm{p}=0.020]$, and number of antihypertensive medications $[\operatorname{Exp}(\mathrm{B})=2.32,95 \% \mathrm{CI}: 1.16-4.65$, $\mathrm{p}=0.017)]$ were risk factors for diastolic dysfunction in logistic regression analysis. AAC scores $\geq 5[\operatorname{Exp}(\mathrm{B})=$ 8.04, 95\% CI: $1.29-50.23, \mathrm{p}=0.026]$ and number of antihypertensive medications $[\operatorname{Exp}(\mathrm{B})=2.30,95 \%$ CI: $1.07-$ $4.97, \mathrm{p}=0.034$ ] were independent predictors of diastolic dysfunction in multiple logistic regression analysis (table 5).

\section{Discussion}

Aortic arch calcification volume measured by multidetector computed tomography was known to be an independent risk factor for LV diastolic dysfunction, which was estimated as the $\mathrm{E} / \mathrm{E}^{\prime}$ ratio in a previous study [5]. Our present study also demonstrated that significant VC on plain radiographs was associated with $\mathrm{E} / \mathrm{E}^{\prime}$ ratio, and AAC scores $\geq 5$ on plain radiograph were closely associated with LV diastolic dysfunction in dialysis patients. The development and progression of diastolic dysfunction is a multifactorial process. The known predisposing factors for diastolic dysfunction include old age, obesity, hypertension, and diabetes. It has been demonstrated that VC results in hemodynamic alterations such as reduced compliance of large arteries and autonomic dys- 
Table 2. Comparison of clinical, laboratory and echocardiographic characteristics according to diastolic dysfunction

\begin{tabular}{|c|c|c|c|}
\hline & $\begin{array}{l}E / E^{\prime} \text { ratio } \leq 15 \\
(n=47)\end{array}$ & $\begin{array}{l}\mathrm{E} / \mathrm{E}^{\prime} \text { ratio }>15 \\
(\mathrm{n}=9)\end{array}$ & $\mathrm{p}$ \\
\hline Age, years & $54.9 \pm 10.4$ & $58.7 \pm 8.8$ & 0.218 \\
\hline Male, n (\%) & $18(38.3)$ & $4(44.4)$ & 0.727 \\
\hline Diabetes, n (\%) & $22(46.8)$ & $6(66.7)$ & 0.469 \\
\hline CAD history, n (\%) & $8(17.4)$ & $5(55.6)$ & 0.026 \\
\hline Dialysis duration, months & $37.4 \pm 28.7$ & $46.4 \pm 28.7$ & 0.354 \\
\hline $\mathrm{BMI}$ & $23.5 \pm 3.1$ & $22.8 \pm 4.1$ & 0.696 \\
\hline Systolic BP, mm Hg & $144.5 \pm 28.2$ & $154.3 \pm 7.9$ & 0.149 \\
\hline Diastolic BP, mm Hg & $79.7 \pm 13.5$ & $79.3 \pm 17.9$ & 0.785 \\
\hline Pulse pressure, $\mathrm{mm} \mathrm{Hg}$ & $65.5 \pm 23.4$ & $75.0 \pm 15.5$ & 0.236 \\
\hline Valve calcification & $0.8 \pm 0.8$ & $0.8 \pm 1.0$ & 0.795 \\
\hline Significant VC, n (\%) & $26(55.3)$ & 8 (88.9) & 0.074 \\
\hline VC of feet, n (\%) & $19(40.4)$ & $4(44.4)$ & 1.000 \\
\hline \multicolumn{4}{|l|}{$\mathrm{VC}$ of hand and pelvis $\geq 3$, } \\
\hline $\mathrm{AAC} \geq 5, \mathrm{n}(\%)$ & $13(28.3)$ & $7(77.8)$ & 0.008 \\
\hline $\mathrm{LV}$ mass index, $\mathrm{g} / \mathrm{m}^{2}$ & $109.4 \pm 25.3$ & $137.4 \pm 26.1$ & 0.013 \\
\hline Ejection fraction, \% & $59.1 \pm 7.5$ & $49.4 \pm 14.2$ & 0.021 \\
\hline Left atrium volume, $\mathrm{ml}$ & $59.2 \pm 17.6$ & $87.4 \pm 23.1$ & 0.002 \\
\hline $\mathrm{E}, \mathrm{cm} / \mathrm{s}$ & $63.4 \pm 16.3$ & $94.3 \pm 21.0$ & $<0.001$ \\
\hline $\mathrm{E}^{\prime}, \mathrm{cm} / \mathrm{s}$ & $7.2 \pm 2.0$ & $5.2 \pm 1.1$ & 0.001 \\
\hline $\mathrm{E} / \mathrm{E}^{\prime}$ ratio & $9.2 \pm 2.5$ & $18.1 \pm 2.4$ & $<0.001$ \\
\hline Hemoglobin, g/dl & $10.4 \pm 1.0$ & $10.4 \pm 1.3$ & 0.800 \\
\hline Creatinine, mg/dl & $10.0 \pm 2.8$ & $9.3 \pm 3.5$ & 0.441 \\
\hline Cholesterol, mg/dl & $165.4 \pm 46.0$ & $151.6 \pm 24.1$ & 0.585 \\
\hline $\mathrm{HDL}, \mathrm{mg} / \mathrm{dl}$ & $41.1 \pm 11.2$ & $38.0 \pm 6.9$ & 0.652 \\
\hline $\mathrm{LDL}, \mathrm{mg} / \mathrm{dl}$ & $90.5 \pm 38.1$ & $76.1 \pm 16.1$ & 0.395 \\
\hline Triglyceride, mg/dl & $155.6 \pm 101.5$ & $148.0 \pm 96.7$ & 0.952 \\
\hline Albumin, mg/dl & $3.9 \pm 0.3$ & $4.0 \pm 0.3$ & 0.805 \\
\hline $\mathrm{CRP}, \mathrm{mg} / \mathrm{dl}$ & $0.4 \pm 1.0$ & $0.4 \pm 0.4$ & 0.078 \\
\hline \multicolumn{4}{|l|}{ Number of anti-HT } \\
\hline medication & $2.43 \pm 1.5$ & $3.9 \pm 0.8$ & 0.005 \\
\hline
\end{tabular}

$\mathrm{BP}=$ Blood pressure $\mathrm{HDL}=$ high-density lipoprotein cholesterol; LDL = low-density lipoprotein cholesterol. CRP = C-reactive protein; HT = hypertension.

function [23]. In addition, pulse wave velocity as a determinant of LV hypertrophy was highly associated with not only $\mathrm{VC}$, but also $\mathrm{E} / \mathrm{E}^{\prime}$ ratio in dialysis patients $[5,24]$. Therefore, frequently detected VC in dialysis patients may have an effect on the development and progression of diastolic dysfunction. Blood pressure was not found to be related with diastolic dysfunction or $\mathrm{E} / \mathrm{E}^{\prime}$ ratio in this study. However, considering the number of antihypertensive medications, it can be assumed that blood pressure is related with the development and progression of diastolic dysfunction. It is of note that significant VC on
Table 3. Correlation between $\mathrm{E} / \mathrm{E}^{\prime}$ ratio and related parameters

\begin{tabular}{lrr}
\hline & $\mathrm{r}$ & $\mathrm{p}$ \\
\hline Age, years & 0.259 & 0.054 \\
CAD history & 0.291 & 0.029 \\
Dialysis duration, months & 0.036 & 0.794 \\
LV mass index, g/m ${ }^{2}$ & 0.351 & 0.009 \\
Left atrium volume & 0.608 & $<0.001$ \\
Ejection fraction, \% & -0.191 & 0.159 \\
Significant VC & 0.325 & 0.015 \\
Feet calcification & 0.138 & 0.310 \\
Hand and pelvis calcification $\geq 3$ & 0.342 & 0.010 \\
AAC $\geq 5$ & 0.396 & 0.003 \\
Valve calcification & 0.090 & 0.526 \\
\hline
\end{tabular}

Table 4. Independent factors associated with $\mathrm{E} / \mathrm{E}^{\prime}$ ratio

\begin{tabular}{llll}
\hline Variables & Standardized coefficient & $\mathrm{t}$ & $\mathrm{p}$ \\
\hline Age & 0.304 & 2.791 & 0.008 \\
LA volume & 0.536 & 4.932 & 0.000 \\
AAC scores $\geq 5$ & 0.296 & 2.637 & 0.012 \\
\hline
\end{tabular}

Multiple linear regression analysis was used for analysis. $\mathrm{LA}=$ Left atrium.

Table 5. Independent factors associated with diastolic dysfunction

\begin{tabular}{llll}
\hline Variables & $\operatorname{Exp}(\mathrm{B})$ & $\mathrm{CI}$ & $\mathrm{p}$ \\
\hline AAC scores $\geq 5$ & 8.04 & $1.29-50.23$ & 0.026 \\
Number of anti-HT medication & 2.30 & $1.07-4.97$ & 0.034 \\
\hline
\end{tabular}

Logistic regression analysis was used for analysis. HT = Hypertension.

plain radiographs and the numbers of antihypertensive medications give clues to possible diastolic dysfunction in dialysis patients.

Age was an independent factor, but diabetes was not an independent factor correlated with the AAC score on lateral lumbar spine radiographs $[14,16]$. In contrast, diabetes was a consistent independent factor, but age was not associated with a VC score of the hands and pelvis $\geq 3$ on plain radiographs and medial artery calcification of the feet on plain radiographs in dialysis patients $[9,16]$. Based on these results, different demographic factors and 
Fig. 1. Comparison of the $\mathrm{E} / \mathrm{E}^{\prime}$ ratio ac-
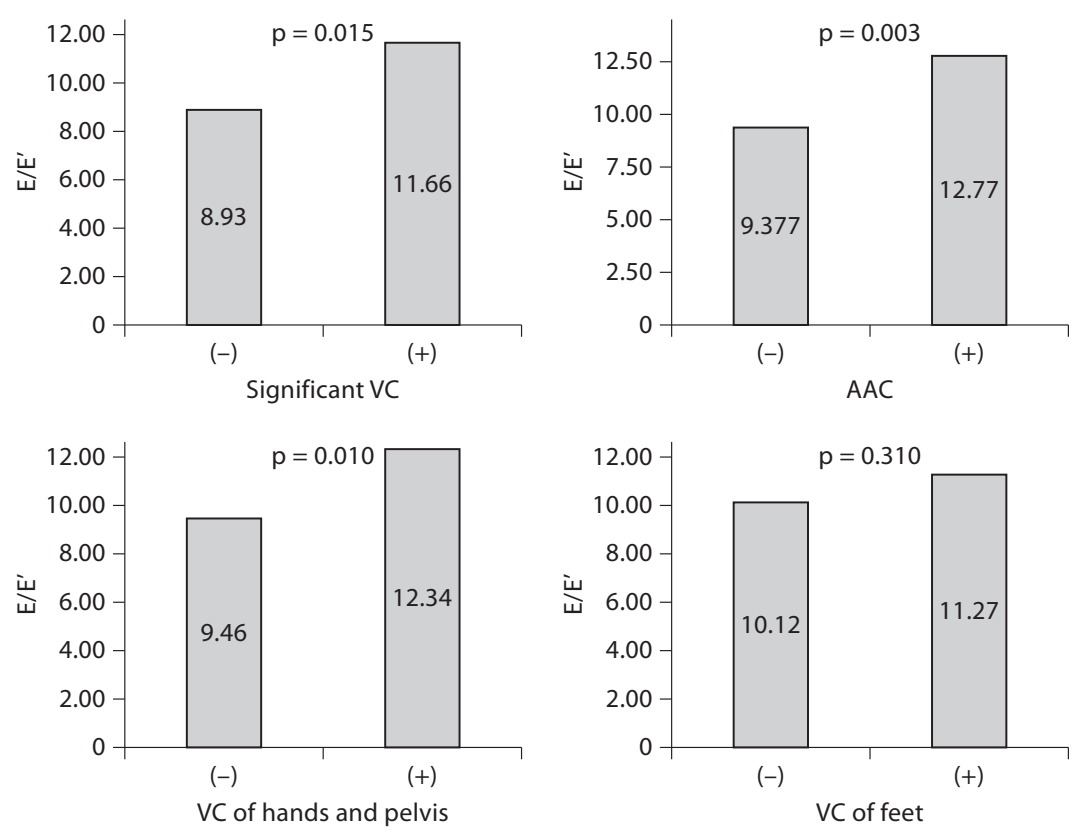
cording to the VC sites.

conditions may be partially related to the formation of $\mathrm{VC}$ according to location and size of the artery. AAC on lateral lumbar spine radiographs is definitely associated with LV diastolic dysfunction and $\mathrm{E} / \mathrm{E}^{\prime}$ ratio, but $\mathrm{VC}$ of the feet was not related with LV diastolic dysfunction in our present study. The VC score of the hand and pelvis may predict diastolic dysfunction based on the $\mathrm{E} / \mathrm{E}^{\prime}$ ratio. However, VC score of the hand and pelvis as a predictor of diastolic dysfunction is less significant than AAC scores based on our study. The significance of $\mathrm{VC}$ as a predictor of diastolic dysfunction is also dependent on the location and size of the artery. AAC indicates large artery calcification, $\mathrm{VC}$ of the hand and pelvis indicates large and peripheral artery calcification, and VC of the feet signify peripheral artery calcification. It is of note that an AAC score $\geq 5$ on plain radiograph compared to other VC sites is the most reliable marker for prediction of the presence of diastolic dysfunction and higher E/E' ratio without echocardiography.

The noninvasive assessment of LV filling pressure without cardiac catheterization can be an important clinical tool. An $\mathrm{E} / \mathrm{E}^{\prime}$ ratio $>15$ is a reliable marker for predicting LV end-diastolic pressure $>15 \mathrm{~mm} \mathrm{Hg}$ in the endstage renal disease population [21]. In addition, patients with an $\mathrm{E} / \mathrm{E}^{\prime}$ ratio $>15$ can be classified as having elevated filling pressure and diastolic dysfunction [22]. An
$\mathrm{E} / \mathrm{E}^{\prime}$ ratio $<8$ suggests normal filling pressure. With an $\mathrm{E} / \mathrm{E}^{\prime}$ ratio in the range of $8-15, \mathrm{LV}$ diastolic dysfunction can be assessed by additional information. Therefore, in this study, we defined definite diastolic dysfunction according to an $\mathrm{E} / \mathrm{E}^{\prime}$ ratio $>15$ or $\leq 15$. An $\mathrm{E} / \mathrm{E}^{\prime}$ ratio $>15$ was a better predictor for mortality than classic clinical and echocardiographic data in end-stage renal disease patients [25]. Meanwhile, combining transmitral flow velocity with annular velocity (E/ $\mathrm{E}^{\prime}$ ratio) has been proposed as the single best tool for assessing LV filling pressure and the prognostic significance of an increased E/E' ratio has been established in several studies [26]. The clinical significance of AAC scores $\geq 5$ on plain radiographs should be emphasized because AAC scores $\geq 5$ on plain radiographs were shown to be an important independent factor for an $\mathrm{E} / \mathrm{E}^{\prime}$ ratio $>15$ and $\mathrm{E} / \mathrm{E}^{\prime}$ ratio in this study.

LV diastolic dysfunction is the important determinant for the incidence of cardiovascular events [27]. In the present study, patients with an $\mathrm{E} / \mathrm{E}^{\prime}$ ratio $>15$ showed lower ejection fraction and a higher percentage of CAD history compared to patients with an $\mathrm{E} / \mathrm{E}^{\prime}$ ratio $<15$. Pulsed Doppler transmitral velocities can be used for assessing LV diastolic function, but this parameter is known to be preload-dependent $[28,29]$. Therefore, volume status of dialysis patients may affect assessment of diastolic 
function. On the contrary, the $\mathrm{E} / \mathrm{E}^{\prime}$ ratio has been proposed as a new method because it is relatively preloadindependent $[30,31]$. Thus, using the $\mathrm{E} / \mathrm{E}^{\prime}$ ratio compared to only using transmitral velocities is much more correct for evaluation of LV diastolic function. Furthermore, a high $\mathrm{E} / \mathrm{E}^{\prime}$ ratio was reflecting chronic LA and LV volume overload by showing correlation of LA volume and LV mass index in the present study.

The main limitations of our cross-sectional study are the small number of patients evaluated and the observational nature of the study. In addition, all parameters were measured at one time point and invasive measurement of LV filling pressure was not performed simultaneously. Therefore, VC is just a hint for considering the presence of a possible LV diastolic dysfunction and this study does not prove that $\mathrm{VC}$ is the cause of LV diastolic dysfunction. The interpretation of the current study was also limited because data were derived from a very small sample size including only 9 patients with diastolic dysfunction. Despite these limitations, to the best of our knowledge, this study is the first to show an association between diastolic dysfunction and VC evaluated by plain radiographs.

In conclusion, a higher $\mathrm{E} / \mathrm{E}^{\prime}$ ratio, which is a predictor of cardiovascular events and diastolic dysfunction, can possibly be anticipated by checking and evaluating for significant VC, especially AAC and VC of the hand and pelvis in dialysis patients. Furthermore, an AAC score $\geq 5$ is an independent predictor of LV diastolic dysfunction defined by $\mathrm{E} / \mathrm{E}^{\prime}>15$ in dialysis patients.

\section{Acknowledgements}

This study was supported by the research funds from Dong-A University.

\section{References}

1 Silberberg JS, Barre PE, Prichard SS, Sniderman AD: Impact of left ventricular hypertrophy on survival in end-stage renal disease. Kidney Int 1989;36:286-290.

-2 Parfrey PS, Foley RN, Harnett JD, Kent GM, Murray D, Barre PE: Outcome and risk factors of ischemic heart disease in chronic uremia. Kidney Int 1996;49:1428-1434.

- 3 Ito S, Murai S, Sugiura M, Yoshida T, Fukutomi T: Predictors of congestive heart failure in patients on maintenance hemodialysis. Circ J 2007;71:1424-1429.

-4 Tsionfis C, Chatzis D, Dimitriadis K, Stougianos P, Kakavas A, Vlasseros I, et al: Left ventricular diastolic dysfunction is accompanied by increased aortic stiffness in the early stages of essential hypertension: a TDI approach. J Hypertens 2005;23:1745-1750.

5 Fujiu A, Ogawa T, Matsuda N, Ando Y, Nitta $\mathrm{K}$, et al: Aortic arch calcification and arterial stiffness are independent factors for diastolic left ventricular dysfunction in chronic hemodialysis patients. Circ J 2008;72:17681772.

6 Foley RN, Parfrey PS, Sarnak MJ: Clinical epidemiology of cardiovascular disease in chronic renal disease. Am J Kidney Dis 1998; 32:112-119.

7 London GM, Guérin AP, Marchais SJ, Métivier F, Pannier B, Adda H: Arterial media calcification in end-stage renal disease: impact on all-cause and cardiovascular mortality. Nephrol Dial Transplant 2003;18:17311740.
-8 Okuno S, Ishimura E, Kitatani K, Fujino Y, Kohno K, Maeno Y, et al: Presence of abdominal aortic calcification is significantly associated with all-cause and cardiovascular mortality in maintenance hemodialysis patients. Am J Kidney Dis 2007;49:417425.

-9 Adragao T, Pires A, Lucas R, Birne R, Magalhaes L, Goncalves M, et al: A simple vascular calcification score predicts cardiovascular risk in haemodialysis patients. Nephrol Dial Transplant 2004;19:1480-1488.

10 Kidney Disease: Improving Global Outcomes (KDIGO) CKD-MBD Work Group: KDIGO clinical practice guideline for the diagnosis, evaluation, prevention, and treatment of chronic kidney disease-mineral and bone disorder (CKD-MBD). Kidney Int 2009;113:S1-S130.

-11 An WS, Kim SE, Kim KH, Bae HR, Rha SH: Associations between oxidized LDL to LDL ratio, HDL and vascular calcification in the feet of hemodialysis patients. J Korean Med Sci 2009;24:115-120.

12 Wilson PW, Kauppila LI, O’Donnel CJ, Kiel DP, Hannan M, Polak JM, et al: Abdominal aortic calcific deposits are an important predictor of vascular morbidity and mortality. Circulation 2001;103:1529-1534.

13 Kauppila LI, Polak JF, Cupples LA, Hannan MT, Kiel DP, Wilson PW: New indices to classify location, severity and progression of calcific lesions in the abdominal aorta: a 25-years follow-up study. Atherosclerosis 1997; 132:245-250.
14 Honkanen E, Kauppila L, Wikstrom B, Rensma PL, Krzesinski JM, Aasarod K, et al: Abdominal aortic calcification in dialysis patients: results of the CORD study. Nephrol Dial Transplant 2008;23:4009-4015.

15 Verbeke F, Van Bisen W, Honkanen E, Wikstrom B, Jensen PB, Krzesinski JM, et al: Prognostic value of aortic stiffness and calcification for cardiovascular events and mortality in dialysis patients: outcome of the Calcification Outcome in Renal Disease (CORD) study. Clin J Am Soc Nephrol 2011;6:153-159.

16 Kim JM, Kim JM, Lee SM, Ryu SH, Kim KH, Kim SE, et al: Comparison of vascular calcification scores on plain radiographs to predict coronary artery disease according to dialysis modality. Korean J Nephrol 2011;30: 292-301.

17 Devereux RB, Alonso DR, Lutas EM, Gottlieb GJ, Campo E, Sachs I, et al: Echocardiographic assessment of left ventricular hypertrophy: comparison to necropsy findings. Am J Cardiol 1986;57:450-458.

18 Oki T, Tabata T, Yamada H, Wakatsuki T, Shinohara H, Nishikado A, et al: Clinical application of pulsed Doppler tissue imaging for assessing abnormal left ventricular relaxation. Am J Cardiol 1997;79:921-928.

-19 Talreja DR, Nishimura RA, Oh JK: Estimation of left ventricular filling pressure with exercise by Doppler echocardiography in patients with normal systolic function: a simultaneous echocardiographic-cardiac catheterization study. J Am Soc Echocardiogr 2007;20:477-479. 
20 Kimura H, Takeda K, Tsuruya K, Mukai H, Muto Y, Okuda $\mathrm{H}$, et al: Left ventricular mass index is an independent determinant of diastolic dysfunction in patients on chronic hemodialysis: a tissue Doppler imaging study. Nephron Clin Pract 2011;117:c67-73.

-21 Sharma R, Pellerin D, Gaze DC, Mehta RL, Gregson H, Streather CP, et al: Mitral peak Doppler E-wave to peak mitral annulus velocity ratio is an accurate estimate of left ventricular filling pressure and predicts mortality in end-stage renal disease. J Am Soc Echocardiogr 2006;19:266-273.

22 Ommen SR, Nishimura RA, Appleton CP, Miller FA, Oh JK, Redfield MM, et al: Clinical utility of Doppler echocardiography and tissue Doppler imaging in the estimation of left ventricular filling pressures: a comparative simultaneous Doppler-catheterization study. Circulation 2000;102:1788-1794.
23 Chesterton LJ, Sigrist MK, Bennett T, Taal MW, Mclntyre CW: Reduced baroreflex sensitivity is associated with increased vascular calcification and arterial stiffness. Nephrol Dial Transplant 2005;20:1140-1147.

24 Raggi P, Bellasi A, Ferramosca E, Islam T, Muntner P, Block GA: Association of pulse wave velocity with vascular and valvular calcification in hemodialysis patients. Kidney Int 2007;71:802-807.

25 Wang AY, Wang M, Lam CW, Chan IH, Zhang Y, Sanderson JE: Left ventricular filling pressure by Doppler echocardiography in patients with end-stage renal disease. Hypertension 2008;52:107-114

26 Bruch C, Klem I, Breithardt G, Wichter T, Gradaus R: Diagnostic usefulness and prognostic implications of the mitral E/E' ratio in patients with heart failure and severe secondary mitral regurgitation. Am J Cardiol 2007;100:860-865.

-27 Barberato SH, Bucharles SG, Sousa AM, Costantini CO, Costantini CR, Pecoits-Filho R: Prevalence and prognostic impact of diastolic dysfunction in patients with chronic kidney disease on hemodialysis. Arq Bras Cardiol 2010;94:457-462.
28 Choong CY, Herrmann HC, Weyman AE, Fifer MA: Preload dependence of Dopplerderived indexes of left ventricular diastolic function in humans. J Am Coll Cardiol1987; 10:800-808.

29 Stoddard MF, Pearson AC, Kern MJ, Ratcliff J, Mrosek DG, Labovitz AJ: Influence of alteration in preload on the pattern of left ventricular diastolic filling as assessed by Doppler echocardiography in humans. Circulation 1989;79:1226-1236.

30 Sohn DW, Chai IH, Lee DJ, Kim HC, Kim HS, Oh BH, et al: Assessment of mitral annulus velocity by Doppler tissue imaging in the evaluation of left ventricular diastolic function. J Am Coll Cardiol 1997;30:474480.

31 Garcia MJ, Thomas JD, Klein AL: New Doppler echocardiographic applications for the study of diastolic function. J Am Coll Cardiol 1998;32:865-887. 